\title{
Geographical origin discrimination of Korean variety, Angelica gigas Nakai by using TDU (Thermal Desorption Unit)-GC/MS
}

\author{
Mi-Na Lee ${ }^{1} \cdot$ Yoon-Suk Kim² ${ }^{2}$ Won-Il Kim ${ }^{3} \cdot$ Jeong-Gyu Kim ${ }^{3} \cdot$ Oh-Kyung Kwon ${ }^{3}$ \\ TDU-GC/MS를 이용한 한국품종 참당귀 국산 판별 기법 \\ 이미나 ${ }^{1} \cdot$ 김윤석 ${ }^{2}$ 김원일 ${ }^{3}$ 김정 $^{3} \cdot$ 권오경 $^{3}$
}

Received: 7 October 2019 / Accepted: 30 December 2019 / Published Online: 31 March 2020

(C) The Korean Society for Applied Biological Chemistry 2020

\begin{abstract}
The objective of this study was to develop a fast and accurate method of variety discrimination and geographical discrimination origin of Korean angelica (Korean variety, Angelica gigas Nakai) by using TDU-GC/MS. Two peaks of decursin and decursinol, which are coumarin derivatives were identified in the range of Total Ion Chromatogram (TIC) RT 26.9-27.2 of the Korean angelica by GC/MS analysis at the time of condensation in a refrigerated condensation system after thermal desorption of sample extracts. In case of Chinese angelica (Chinese variety), ligustilide peak was detected at the RT 17.2. In order to investigate the difference of volatile components according to the geographical origin of Korean variety, the mass spectra were measured by TDU-GC/MS at the range of $\mathrm{m} / \mathrm{z}$ 40-400 amu. The TIC of domestic cultivation and Chinese cultivation of the Korean variety, Angelica gigas Nakai showed the same tendency as a whole. However, in partial scans of TIC, two peaks detected at 15.54 and 16.05 of RT showed different peak patterns between

Oh-Kyung Kwon $(\bowtie)$

E-mail: okkwon@korea.ac.kr

${ }^{1}$ Nutraceutical Food R\&D Center, Kolmar BNH, Sejong 30003, Republic of Korea

${ }^{2}$ Water Quality Research Center, K-water, Daejeon 34350, Republic of Korea

${ }^{3}$ OJERI, Korea University, 145 Anam-ro, Sungbuk-gu, Seoul 02841, Repulic of Korea

This is an Open Access article distributed under the terms of the Creative Commons Attribution Non-Commercial License (http://creativecommons. org/licenses/by-nc/3.0/) which permits unrestricted non-commercial use, distribution, and reproduction in any medium, provided the original work is properly cited.
\end{abstract}

Korean angelica (Korean variety) cultivated in Korea and in China. The ratio of Peak A (RT 15.54) and B (RT 16.05) was 0.00.2 for domestic cultivation and 0.5-2.8 for Chinese cultivation, confirming the possibility of discriminating origin by comparing the TIC peak pattern of TDU-GC/MS.

Keywords Discrimination · Geographical Origin · Korean Angelica (Angelica gigas Nakai) · Peak Pattern Comparison · TDU-GC/MS Analysis

\section{서 론}

한국 내 대표적인 약용작물 중 하나인 당귀는 pyranocoumarin 계 화합물인 decursin, decursinol 및 nodakenin과 휘발성 향기 성분인 $\alpha$-pinene, $\beta$-eudesmol 등의 다양한 약리성분을 함유하고 있어 사물탕 및 각종 한약재료로서 사용되고 있다[1-8].

한국품종 당귀(Korean angelica)인 참당귀는 2016년 생산량이 1,398 톤으로, 최근 수요증가로 인해 재배면적 확대가 요구되고 있으나 저가의 중국품종 당귀(중당귀)가 불법변칙 유통되어 혼 합 사용되고 있어 한국품종 당귀의 가격 및 출하 안정을 꾀할 수 없는 실정이다. 또한, 한국품종 당귀가 중국 등에서 재배된 후에 한국 내로 유입된 경우, 한국 내에서 재배된 한국품종의 당귀와 외형 및 내부 형태학적 형질에 차이가 없어 육안으로 원산지를 판별하는 것은 어려움이 있다. 이와 같은 농산물의 불 법 유통을 방지하기 위해서는 신속 정확한 한국품종 당귀를 판 별해내는 방법이 요구 된다.

당귀의 원산지를 판별하기 위한 종래 기법으로는 파이로시퀀 싱법에 의한 당귀의 종간 유전자 감별 키트에 관한 것으로서, 중당귀(중국품종 당귀), 일당귀(일본품종 당귀), 참당귀(한국품종 
당귀)의 유전자형을 분석하고 당귀의 종간 특이성 시퀀싱 프라 이머를 고안하여 당귀의 종간 연관성 및 유전적 변이를 평가하 기 위한 감별 키트(한국 등록특허 제0720864호)와 가속용매 추 출기 및 기체크로마토그래피를 이용한 분석을 통해 토당귀(참 당귀), 일당귀, 및 중국당귀를 식별하는 방법이 있으나(한국 공 개특허 제2006-0081390) 이들 방법은 특정 유전자 또는 성분을 검출하여 단지 당귀의 품종만을 확인하는 기술로서, 재배지가 한국인지를 판별하여 $100 \%$ 토종 한국품종의 당귀를 가려내는 것은 불가능하다.

따라서, 본 연구의 목적은 교반막대 흡착 추출법 및 열탈착 장치를 가지는 기체크로마토그래피-질량분석 기술을 이용하여, 한국품종의 당귀를 판별하고 재배지가 한국지역인 $100 \%$ 토종 한국품종 당귀를 판별할 수 있는, 한국품종 당귀 판별 기법을 설정하고자 하였다.

\section{재료 및 방법}

\section{당귀 시료}

본 연구에서는 시중에서 유통되고 있는 당귀를 건조된 상태로 참당귀 국내 재배산 15 점, 참당귀 중국 재배산 15 점, 그리고 중 당귀를 각각 15 종을 구입하였으며, 이를 분쇄하여 시료로 사용 하였다.

\section{당귀 중 활성성분 분석법}

$50 \mathrm{~mL}$ Tube에 시료 $3 \mathrm{~g}$ 과 $\mathrm{MeOH} 30 \mathrm{~mL}$ 를 넣은 다음 $70^{\circ} \mathrm{C}$ 에 서 2 시간 동안 가열하였다. 가열 완료 후 1 시간 동안 초음파기 를 이용하여 당귀를 추출하였으며, 당귀 추출물에 대해 원심분 리(3,000 rpm, 10분)를 수행하여 침전물을 제거하였다.

PDMS (Polydimethylsiloxane)로 충진된 Twister (Gerstel사, 교 반막대 길이: $10 \mathrm{~mm}, \mathrm{PDMS}$ 막 두께: $1.0 \mathrm{~mm}$ )가 있는 $20 \mathrm{~mL}$ vial에 $10 \mathrm{~mL}$ 증류수와 10 배 추출 희석액을 $20 \mu \mathrm{L}$ 투입하고 $1,200 \mathrm{rpm}$ 의 속도로 1 시간 동안 교반하여, 당귀 추출물이 충분히
Table 1 TDU-GC/MS conditions for the discrimination analysis of Korean angelica

\begin{tabular}{|c|c|c|}
\hline \multirow{4}{*}{$\mathrm{GC}$} & Column & DB-5 $(30 \mathrm{~m} \times 0.25 \mathrm{~mm} \times 0.25 \mu \mathrm{m})$ \\
\hline & Injection mode & Splitless mode \\
\hline & Oven temp & $50{ }^{\circ} \mathrm{C}(5 \mathrm{~min})-10^{\circ} \mathrm{C} / \mathrm{min}-280^{\circ} \mathrm{C}(5 \mathrm{~min})$ \\
\hline & gas flow & $\mathrm{He}(99.9999 \%), 1.4 \mathrm{~mL} / \mathrm{min}$ \\
\hline \multirow{3}{*}{ MSD } & Ionization & EI, $70 \mathrm{eV}$, SCAN mode \\
\hline & Source temp. & $150^{\circ} \mathrm{C}$ \\
\hline & Transfer temp. & $230{ }^{\circ} \mathrm{C}$ \\
\hline \multirow{3}{*}{ TDU } & Initial & $40^{\circ} \mathrm{C}(0.5 \mathrm{~min})$ \\
\hline & Transfer & $300{ }^{\circ} \mathrm{C}$, splitless mode \\
\hline & Ramp & $60{ }^{\circ} \mathrm{C} / \mathrm{min}-280{ }^{\circ} \mathrm{C}(5 \mathrm{~min})$ \\
\hline \multirow{2}{*}{ CIS } & Initial & $-20{ }^{\circ} \mathrm{C}(0.5 \mathrm{~min})$ \\
\hline & Ramp & $12{ }^{\circ} \mathrm{C} / \mathrm{sec}-300{ }^{\circ} \mathrm{C}(10 \mathrm{~min})$ \\
\hline
\end{tabular}

흡착된 다음 교반 막대를 건져 티슈로 물기를 닦아 건조시켰다.

Twister에 흡착된 성분은 $\mathrm{TDU}$ 에 의해 탈착되어 $\mathrm{GC} / \mathrm{MS}$ 로 성 분을 확인하였다. 분석은 TDU-GC/MS (Agilent 7890B/HP 5977A Mass selective detector)를 이용하였으며 분석조건은 Table 1과 같다. 분리용 컬럼은 DB-5MS (5\% Phenyl 95\% Methylpolysiloxane)을 사용하였다.

\section{결과 및 고찰}

\section{한국 및 중국품종 당귀의 기기분석 결과}

분석결과 Total Ion Chromatogram (TIC)의 RT 17.5-18.4에서 검출되는 피크는 Ligustilide로서 중국품종 당귀에서만 확인되었 으며, 또한 RT 26.2-27.2 사이에 검출되는 2개의 피크는 Decursin과 Decosinol로서 한국에서 재배된 한국품종의 당귀 및 중국에서 재배된 한국품종의 당귀에서는 매우 높은 존재비로서 확인이 되지만, 중국품종 당귀에서는 거의 검출되지 않았다. 이

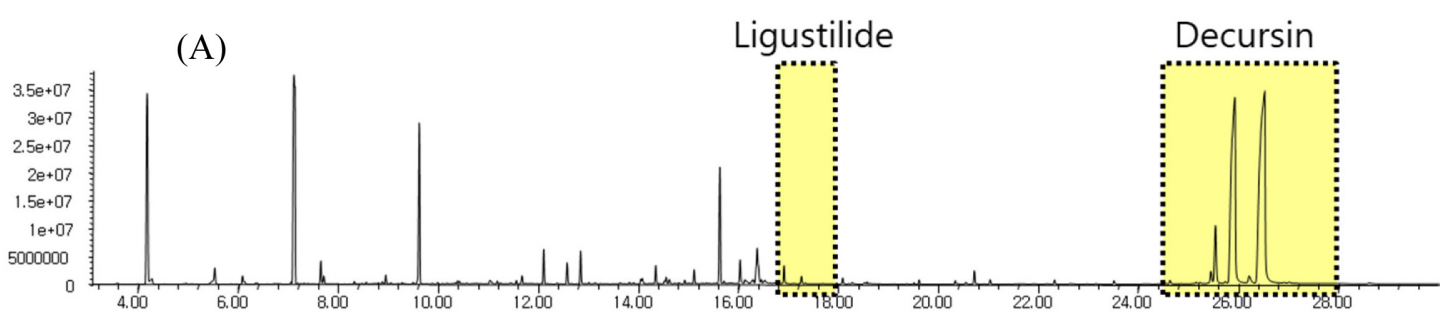

(B)

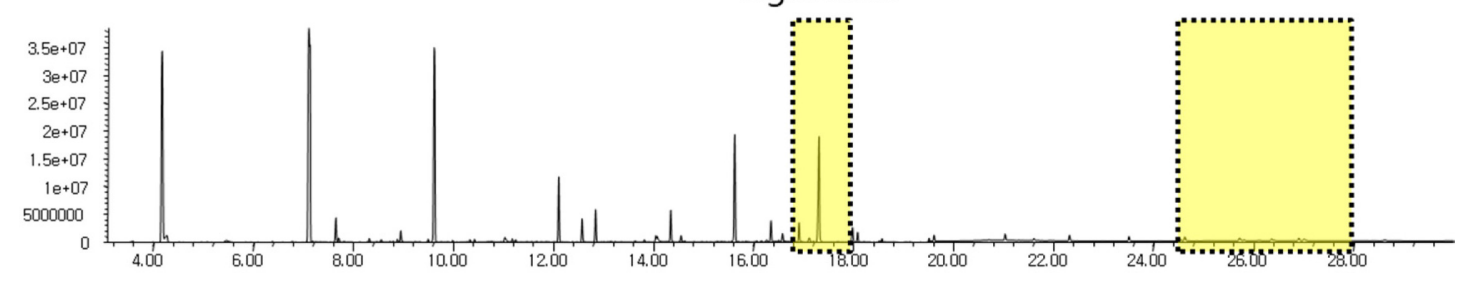

Fig. 1 Comparative mass chromatograms of Korean angelica, Angelica gigas Nakai (A) and Chinese angelica, Angelica sinensis Diels (B) for variety discrimination 


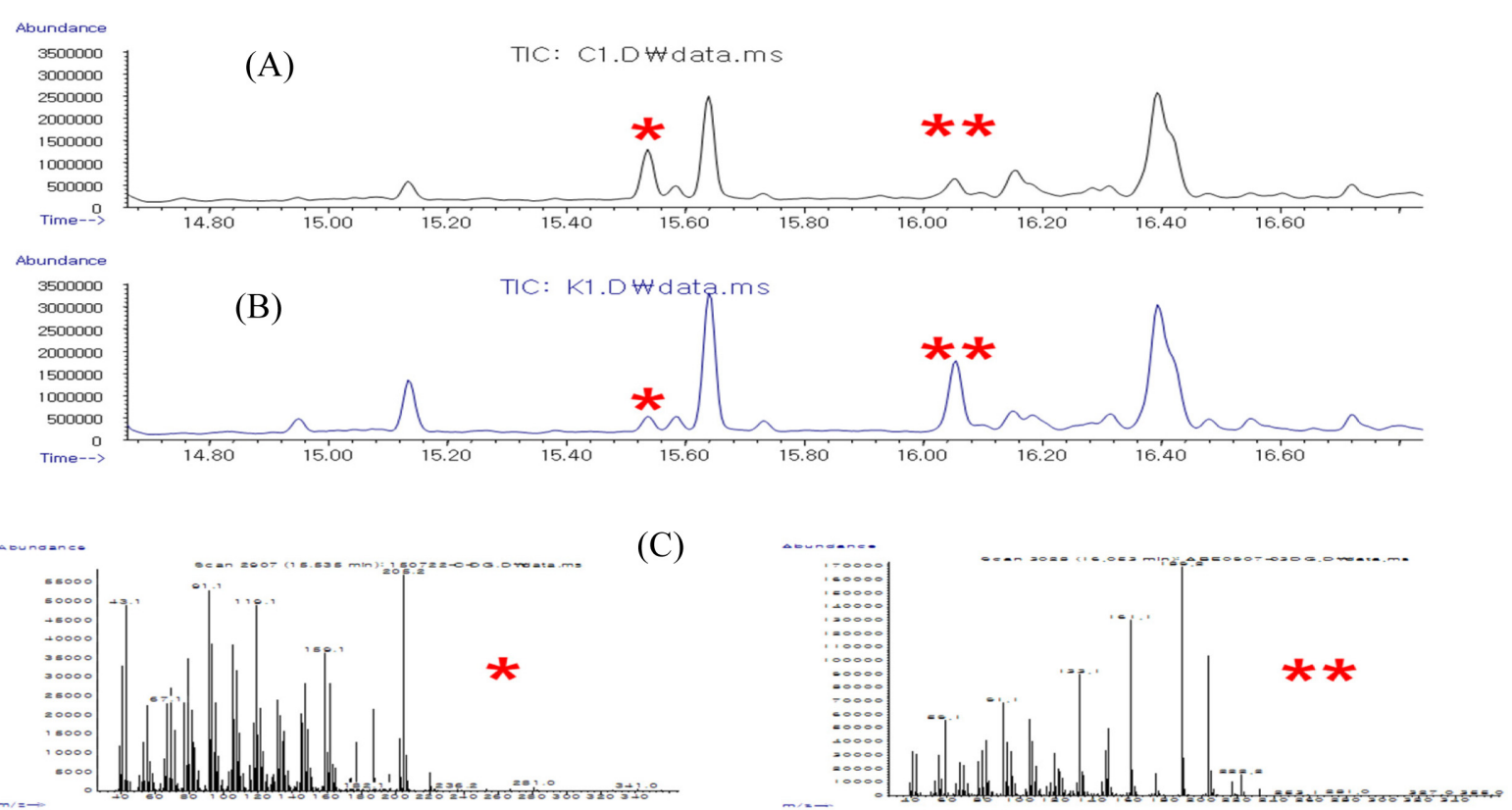

Fig. 2 Comparative mass chromatograms of Chinese cultivation (A) and domestic cultivation (B) for geographical origin discrimination of Korean angelica, Angelica gigas Nakai and mass spectra $(\mathrm{C})$ of peaks $(*, * *)$ detected in chromatograms

(A) TIC of Korean angelica (Chinese cultivation)

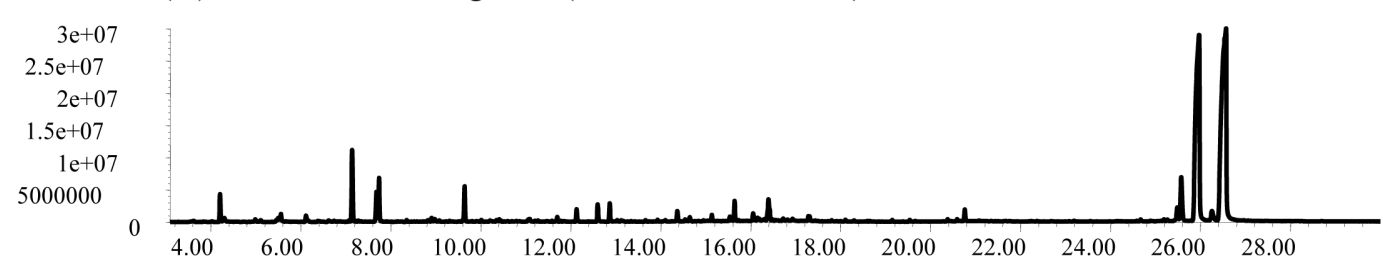

(B) TIC of Korean angelica (Domestic cultivation)

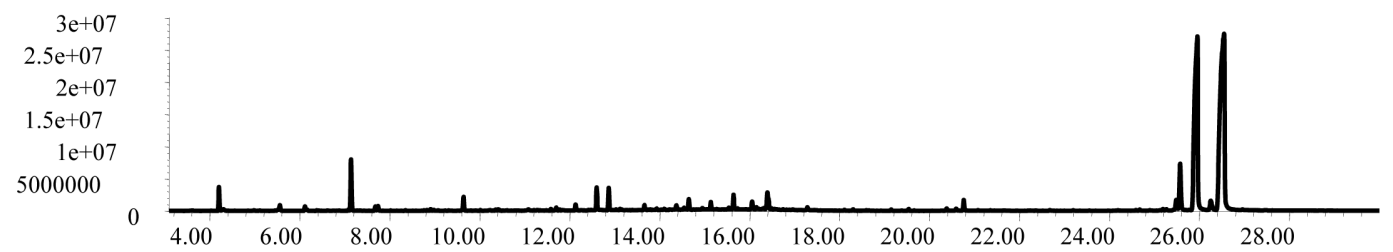

(C) Discrimination by Peak Pattern of TIC

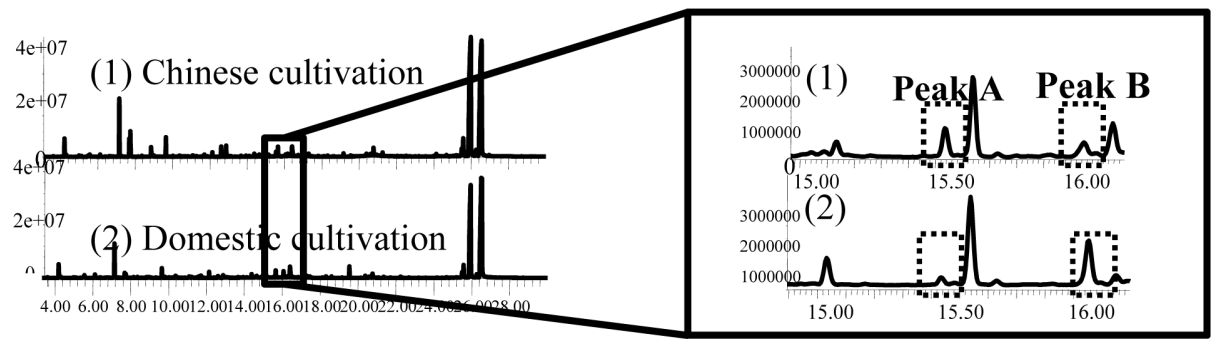

Fig. 3 Comparative peak pattern of Chinese cultivation and domestic cultivation for geographical origin discrimination of Korean angelica, Angelica gigas Nakai 
Table 2 Peak pattern evaluation of domestic cultivation (K) and Chinese cultivation (C) for geographical origin discrimination of Korean angelica, Angelica gigas Nakai

\begin{tabular}{cccc}
\hline \hline Classification & Area of Peak A & Area of Peak B & A/B \\
\hline K1 (C1) $^{\text {b) }}$ & $3,643,262(16,231,415)$ & $49,898,189(9,714,562)$ & $0.1(1.7)$ \\
K2 (C2) & $3,287,966(4,970,550)$ & $60,092,278(9,933,692)$ & $0.1(0.5)$ \\
K3 (C3) & $10,411,776(16,167,290)$ & $65,286,774(11,795,381)$ & $0.2(1.4)$ \\
K4 (C4) & $1,802,286(9,482,900)$ & $25,349,632(20,498,680)$ & $0.1(0.5)$ \\
K5 (C5) & $3,894,807(12,228,100)$ & $44,849,763(9,729,756)$ & $0.1(1.3)$ \\
K6 (C6) & $4,926,607(13,800,828)$ & $38,355,128(10,967,164)$ & $0.1(1.3)$ \\
K7 (C7) & $3,462,624(9,683,075)$ & $24,752,769(13,300,416)$ & $0.1(0.7)$ \\
K8 (C8) & $5,691,219(10,365,280)$ & $46,290,427(12,868,575)$ & $0.1(0.8)$ \\
K9 (C9) & $2,340,231(10,160,659)$ & $57,501,847(6,558,090)$ & $0.0(1.5)$ \\
K10 (C10) & $8,260,440(6,061,819)$ & $50,235,807(6,757,023)$ & $0.2(0.9)$ \\
K11 (C11) & $2,888,574(17,473,377)$ & $37,840,241(13,471,768)$ & $0.1(1.3)$ \\
K12 (C12) & $3,984,526(19,741,719)$ & $36,706,926(6,954,324)$ & $0.1(2.8)$ \\
K13 (C13) & $1,593,204(7,822,752)$ & $27,439,266(9,370,060)$ & $0.1(0.8)$ \\
K14 (C14) & $2,108,543(10,970,661)$ & $55,662,529(11,969,029)$ & $0.0(0.9)$ \\
K15 (C15) & $4,285,523(12,145,540)$ & $28,126,277(9,109,058)$ & $0.2(1.3)$ \\
\hline
\end{tabular}

Domestic cultivation of Korea angelica, Angelica gigas Nakai

Chinese cultivation of Korean angelica, Angelica gigas Nakai

러한 결과로부터 분석시료가 한국품종 당귀인지 또는 한국품종 이 아닌지를 판별할 수 있었다(Fig. 1).

\section{한국품종 당귀의 국내 및 중국 재배지역에 따른 TIC 특성}

TIC 부분 scan 결과 RT 15.4 분 내지 16.1 분 사이의 2 개 피크 를 이용하여 한국품종 당귀의 국내 및 중국에서 재배된 당귀를 판별할 수 있었다(Fig. 2). RT 15.54와 16.05에서 검출된 두 개 의 피크는 한국 품종 당귀의 한국과 중국에서 재배된 것에서 피크패턴이 다르게 나타났다.

Fig. 2에서 보는 바와 같이, RT 15.54 에서 $1.5 \times 10^{6}$ 내지 약 $1.5 \times 10^{10}$ 의 존재비를 나타내는 피크의 질량분석 결과 CAS No. 6750-60-3인 물질 (Spathulenol, MW 220, $\mathrm{C}_{15} \mathrm{H}_{24} \mathrm{O}$ )인 것을 알 수 있었다. 또한, RT 16.05 에 $1.5 \times 10^{6}$ 이상의 존재비를 나타내 는 피크에 대해서도 질량분석을 통해 확인하였으며, 그 성분은 CAS No. 74367-33-2인 물질(r-Eudesmol, MW 222, $\mathrm{C}_{15} \mathrm{H}_{26} \mathrm{O}$ ) 임을 알 수 있었다(Fig. 2).

$\mathrm{TIC}$ 에서 선택된 2개의 peak에 대한 peak pattern 결과는 한 국에서 재배된 한국품종 당귀와 한국품종이지만 중국에서 재배 된 중국산 당귀 판별방법을 제시하였다.

Peak pattern은 Fig. 3에 나타낸 바와 같이 TIC 부분 scan의 RT 15.4-16.1 에서 원산지별 peak pattern 차이를 확인할 수 있 었다. Peak A (RT 15.54)와 B (RT 16.05)의 비율은 국내 재 배는 0.0-0.2, 중국 재배의 경우 0.5-2.8 (Table 2)으로서 TDU$\mathrm{GC} / \mathrm{MS}$ 의 TIC peak pattern 비교를 통한 원산지 판별 가능성을 확인하였다.

\section{초 록}

한약재의 불법 유통을 방지하기 위해 신속 정확한 원산지 판별
방법 개발이 필요함에 따라 TDU-GC/MS를 이용하여 한국품종 당귀와 외국품종 당귀를 판별함과 동시에 한국품종 당귀의 재 배지가 한국인지를 판별할 수 있는 기법을 연구하였다. 당귀추 출물을 열탈착 시킨 후 냉각응축시스템에서 응축시켜 일시에 $\mathrm{GC} / \mathrm{MS}$ 로 분석한 결과 국산 품종 당귀(참당귀)는 $\mathrm{TIC}$ 의 $\mathrm{RT}$ 26.9-27.2에서 coumarin 유도체인 decursin과 decursinol peak가 확인되었다. 중국 품종 당귀(중당귀)의 경우 RT 17.2 부근에서 ligustilide의 peak가 검출되었다. 국산 품종 참당귀 원산지에 따 른 휘발성분의 차이를 알아보기 위하여 twister로 흡착하여 TDU-GC/MS로 m/z 40-400 amu 범위에서 mass spectrum을 측정하였다. 참당귀의 국내 및 중국 재배 시료 $\mathrm{TIC}$ 는 전반적으 로 같은 경향을 냈으나 $\mathrm{TIC}$ 를 부분 scan한 결과 RT 15.4-16.1 에서 국내 및 중국 재배의 peak pattern 차이를 확인할 수 있 었다. Peak A (RT 15.54)과 B (RT 16.05)의 비율은 국내 재 배는 0.0-0.2, 중국 재배의 경우 0.5-2.8으로서 TDU-GC/MS의 TIC peak pattern 비교를 통한 원산지 판별 가능성을 확인하였다.

Keywords TDU-GC/MS 분석 · 당귀 - 원산지판별 - 피크패턴 비교 · 한국품종

\section{References}

1. Chi HJ, Kim HS (1988) Studies on essential oils of plants Angelica genus in Korea (1) Essential oils of Angelica gigantis radix. Kor J Pharmacogn 19: 239-247

2. Choi HS, Lee MS, Sawamura M (2002) Constituents of the essential oil of cnidium officinale Makino, a Korean medicinal plant. Flavour Fragrance J 17: 49-53

3. Choi SH, Kim H J (2000) Volatile flavor components of Angelica gigas Nakai by the storage conditions. Korean J Foodsci Technol 32: 513-518

4. Lay HL, Lin WY, Motota Y, Tamai F, Tanabe T (1992) Studies on the 
production and improvement in quality of Angelica acutiloba Kitagawa (1) Effects of manurial elements on the plant growth and yield, extract contents, ligustilide and butylidene phthalide contents of Angelica radix. Shoyakugaku Zasshi 46: 321-327

5. Noro Y, Hisata Y, Okuda K, Kawamura T, Ishikawa I, Sakai E, Tanaka T (1989) Pharmacognostical studies of Angelica radix (1) Phthalide content of wild angelica strains. Shoyakugaku Zasshi 43: 55-58

6. Ryu KS, Hong ND, Kim NY, Kong YY (1990) Studies on the coumarin constituents of the root of Angelica gigas Nakai. Isolation of decursionol angelate and assay of decursinol angelate and decursin. Kor J Phatmacogn 21: 64-68

7. Sekizai H, Agata I, Kimura K (1984) Studies on the variation of ligustilide content for cultivating process of Angelica acutiloba var. acutiloba Kitagawa. Shoyakugaku Zasshi 38: 361-362

8. Seo HY, Yang SH, Shim SL, No KM, Park KS, Song KD, Kim KS (2002) Volatile organic compounds of Angelica gigas Nakio, Korean medicinal herb. Nat Prod Res 21: 265-273 